\title{
Future Schools
}

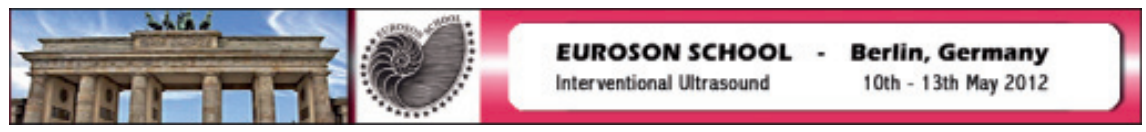

- In collaboration with the Working Group Interventional Ultrasound of DEGUM the second EFSUMB EUROSON-School ,Interventional Ultrasound ` will take place from 10 - 13 May 2012 in Berlin.

The intensive course is designed to provide the basis for sonographic intervention and mediation of interventional techniques that are performed using ultrasound as an imaging method.

- Course organisers: Prof. Dieter Nürnberg (Neuruppin), Prof. Klaus Schlottmann (Unna) and all speakers would appreciate your participation.

For more information, visit www.efsumb.org
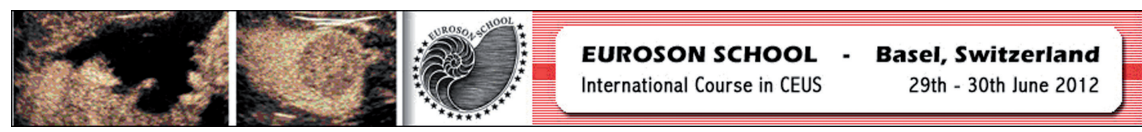

- International course in CEUS

University Hospital Basel, Switzerland

June 29-30, 2012

- Course organisers: Dr. Daniel Weiss, Dr. Joachim Hohmann

Course secretary: Claudia Miescher miescherc@uhbs.ch

Registration fee EUR 250

For course details visit www.efsumb.org
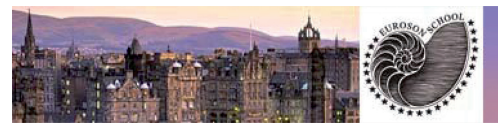

EUROSON SCHOOL - Edinburgh, Scotland Microbubble Ultrasound Imaging Course 25th \& 26th June 2012 at The Holyrood Hotel Edinburgh

- Microbubble ultrasound imaging course

25-26 June 2012

The Holyrood Hotel Edinburgh

This 2 day meeting will aim to present the most significant applications and advances in the various fields of clinical diagnostic and interventional use of Contrast Enhanced Ultrasound (CEUS) in the evaluation of various organs. CME points applied for.

> For more information please contact Mr Behzad Mokri psycy1@hotmail.com 


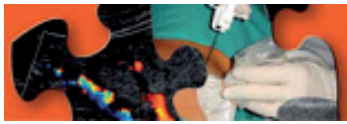

- S. Orsola-Malpighi Hospital, Bologna, Italy

10-12 September 2012

Course organisers: Fabio Piscaglia, Carla Serra and Mirko D’Onofrio

- Topics will include clinical issues in liver and gastro-intestinal diseases and comparative role of multiple imaging modalities. Practical teaching will be held in small groups (max. 4-5 participants per group).

Visit www.efsumb.org

- The EFSUMB Course Book on Ultrasound, edited by Christoph F Dietrich, is now published.

Prof. Luigi Bolondi writes that that the book „fills the gap of learning material about the basic core of ultrasound [and] written by the greatest international experts is beautifully illustrated, but nonetheless extremely cheap“.

Order your copy at $60 €$ (plus P\&P) via the EFSUMB website www.efsumb.org

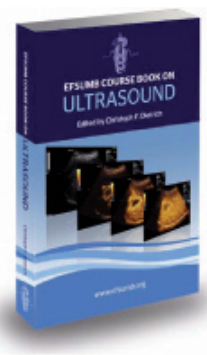

